\title{
Edoxaban Was Effective for the Treatment of Deep Vein Thrombosis and Pulmonary Thromboembolism in a Cancer Patient with Antithrombin III Deficiency
}

\author{
Hiroaki Kawano and Koji Maemura
}

\begin{abstract}
A 57-year-old man with antithrombin III deficiency with deep vein thrombosis and pulmonary thromboembolism after surgery for colon cancer was managed with warfarin and inferior vena cava filtration. After starting chemotherapy for liver metastasis, the control of his prothrombin time-international normalized ratio in response to warfarin began to fluctuate. Warfarin was changed to edoxaban (an oral direct Factor Xa inhibitor), and he had no recurrence of venous thromboembolism or bleeding for approximately 1 year. We conclude that edoxaban could be a useful treatment option for complicated patients with deep vein thrombosis.
\end{abstract}

Key words: antithrombin III deficiency, cancer, thrombus

(Intern Med 55: 3285-3289, 2016)

(DOI: 10.2169/internalmedicine.55.7314)

\section{Introduction}

Venous thromboembolism (VTE), which includes deep vein thrombosis and pulmonary embolism, has an annual overall incidence of approximately $1-2 \%$ and is a severe disorder with major potential complications (including death from pulmonary embolism, recurrent VTE, and disabling post-thrombotic syndrome) $(1,2)$. Although warfarin is an effective anticoagulant for VTE prevention, strict anticoagulation therapy is required for a prolonged period of time, especially for patients with inherited thrombophilia, antiphospholipid syndrome or cancer. Antithrombin (AT) III deficiency is associated with a three-fold to seven-fold higher risk of VTE in comparison to the other thrombophilias (3).

The effects of warfarin can vary according to the patient's intake of vitamin K-containing foods and drug interactions, and frequent monitoring and dose adjustment are required to achieve a suitable prothrombin time-international normalized ratio (PT-INR). Direct oral anticoagulants (DOACs) have recently been used for the initial and long-term treatment of VTE.

The present report describes the case of a cancer patient with VTE and AT III deficiency who was treated with once-
\end{abstract}

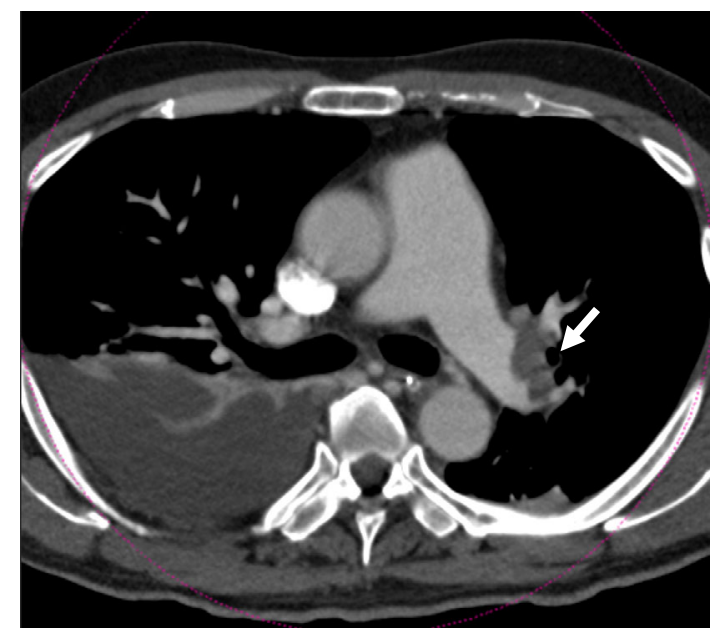

Figure 1. A contrast-enhanced abdominal computed tomography scan shows pulmonary thromboembolism at the left main pulmonary artery (arrow).

daily administration of edoxaban because a stable PT-INR could not be achieved with warfarin due to chemotherapy.

Department of Cardiovascular Medicine, Nagasaki University Graduate School of Biomedical Sciences, Japan

Received for publication February 23, 2016; Accepted for publication March 11, 2016

Correspondence to Dr. Hiroaki Kawano, hkawano@nagasaki-u.ac.jp 

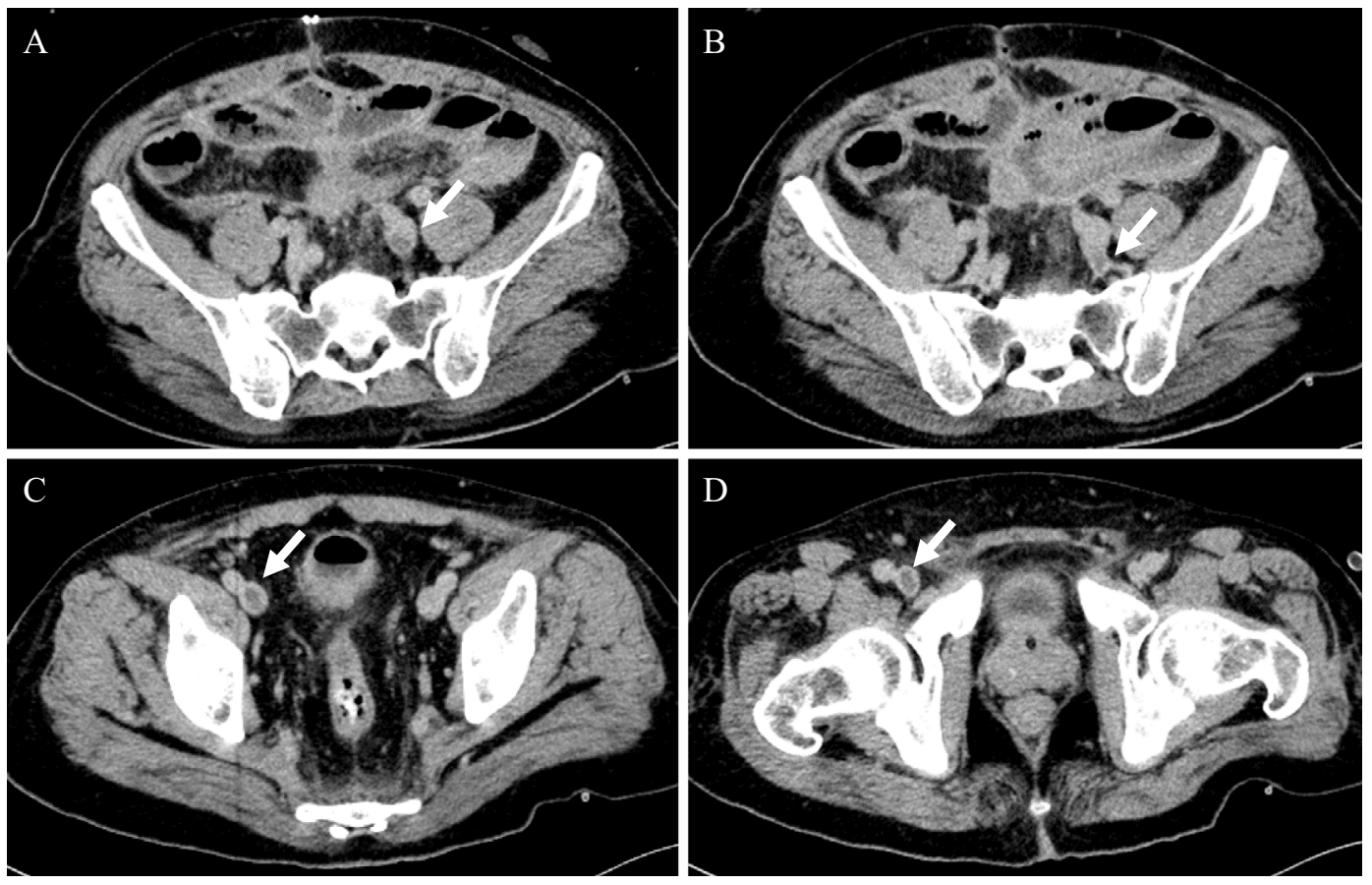

Figure 2. A contrast-enhanced abdominal computed tomography scan detected thrombosis in the left common vein $(A)$, the left internal iliac vein $(B)$, the right external iliac vein $(C)$ and the femoral vein (D).

\section{Case Report}

A 57-year-old man had previously undergone surgery for sigmoid colon cancer in our hospital at 53 years of age. His past medical history included pulmonary thromboembolism and deep vein thrombosis at 51 years of age after an airplane flight from the United States. Since then, he had been treated with warfarin therapy. With regard to his family history, both his brother and daughter had been diagnosed with AT III deficiency.

Seven days after the surgical resection of the patient's colon cancer, follow-up contrast-enhanced computed tomography (CT) incidentally detected a new pulmonary thromboembolism at the left main pulmonary artery (Fig. 1), thrombosis in the left common and internal iliac veins and the right external iliac and femoral veins (Fig. 2). An inferior vena cava filter (IVC) was inserted and urokinase (240,000 units) was intravenously infused in addition to heparin therapy. Anti-thrombin was administered because of the patient's low AT III level (35\%). The IVC filter was left in place, because he had an iodine allergy and experienced transient hypotension after the original contrast-enhanced abdominal CT. Warfarin therapy was deemed effective, and he was discharged from the hospital. He did not experience recurrent VTE during the follow-up period.

Approximately 1 year after the surgical resection of the patient's colon cancer, liver metastasis was detected in the $\mathrm{S} 4$ (6 $\mathrm{cm}$ in diameter) and $\mathrm{S} 6(3.5 \mathrm{~cm}$ in diameter) by magnetic resonance imaging (MRI).

Chemotherapy was initiated with modified FOLFOX6 [oxaliplatin $\left(85 \mathrm{mg} / \mathrm{m}^{2}\right)$, leucovorin $\left(400 \mathrm{mg} / \mathrm{m}^{2}\right), 5-\mathrm{FU}$ (fluorouracil, $400 \mathrm{mg} / \mathrm{m}^{2}$ on day 1), followed by 5 -FU $\left(2,400 \mathrm{mg} / \mathrm{m}^{2}\right.$ by intravenous infusion over 46 hours every 2 weeks)], panitumumab (6 mg/kg every 2 weeks), and antiendothelial growth factor receptor antibodies to decrease the size of metastatic liver tumor. During chemotherapy, the patient's PT-INR ranged from 1.29 to 3.42 , and his D-dimer level ranged from 0.3 to 1.9 despite adjustments to the warfarin dosage (ranging from $3.5 \mathrm{mg}$ to $4.5 \mathrm{mg}$ ). The metastatic liver tumors decreased in size (to $1.5 \mathrm{~cm}$ in $\mathrm{S} 4$ and to $2.5 \mathrm{~cm}$ in the S6), and surgical resection was performed. Seven days after the surgery, a new pulmonary thromboembolism was noted, and he was treated with heparin and AT. Approximately 1 month after the recurrence of the pulmonary thromboembolism, type I AT III deficiency was diagnosed based on the patient's low AT III activity, which was $47 \%$ (normal range, $75-125 \%$ ) and low serum concentration of AT III (11.4 mg/dL; normal range, $15-31 \mathrm{mg} / \mathrm{dL})$ in addition to anti-nuclear antibody, $<20$; anti-phospholipid antibody, $0.8 \mathrm{U} / \mathrm{mL}(<10 \mathrm{U} / \mathrm{mL})$; lupus anti-coagulant, $1.04(<$ 1.3); anti-cardiolipin $\beta_{2}$-glycoprotein I complex antibody, < $1.2 \mathrm{U} / \mathrm{mL}(<3.5 \mathrm{U} / \mathrm{mL})$; protein $\mathrm{C}, 83 \%$ (normal range, 70 $140 \%$ ); and protein S, $107 \%$ (normal range, 60-150\%). The patient's other laboratory data at the time of warfarin treatment are shown in Table 1. These include: platelet count, 240,000/ $\mu \mathrm{L}$; PT-INR, 2.45; activated partial thromboplastin time (APTT), $39.4 \mathrm{~s}$ (normal range, 25.2-34.4 s); fibrinogen, $291 \mathrm{mg} / \mathrm{dL}$ (normal range, 168-329 mg/dL); fibrinogen degradation products (FDP), $11.6 \mu \mathrm{g} / \mathrm{mL}$ (normal range, $<5 \mu \mathrm{g}$ / $\mathrm{mL}$ ); and D-dimer, $7.4 \mu \mathrm{g} / \mathrm{mL}$ (normal range, $<1 \mu \mathrm{g} / \mathrm{mL}$ ).

After the patient's condition improved and after stable 
Table 1. Laboratory Data.

\begin{tabular}{llllll}
\hline WBC & $3,500 \times 10^{3} / \mu \mathrm{L}$ & $\mathrm{Na}$ & $141 \mathrm{mEq} / \mathrm{L}$ & ALT & $16 \mathrm{U} / \mathrm{L}$ \\
$\mathrm{RBC}$ & $3.93 \times 10^{6} / \mu \mathrm{L}$ & $\mathrm{K}$ & $4.4 \mathrm{mEq} / \mathrm{L}$ & ALP & $159 \mathrm{U} / \mathrm{L}$ \\
$\mathrm{Hb}$ & $11.2 \mathrm{~g} / \mathrm{dL}$ & $\mathrm{Cl}$ & $107 \mathrm{mEq} / \mathrm{L}$ & $\mathrm{LDH}$ & $242 \mathrm{U} / \mathrm{L}$ \\
$\mathrm{Hct}$ & $36.2 \%$ & BUN & $18 \mathrm{mg} / \mathrm{dL}$ & $\mathrm{gGTP}$ & $26 \mathrm{U} / \mathrm{L}$ \\
Plt & $24 \times 10^{4} / \mu \mathrm{L}$ & Cre & $1.2 \mathrm{mg} / \mathrm{dL}$ & CK & $31 \mathrm{U} / \mathrm{L}$ \\
PT (INR) & 2.45 & UA & $9.2 \mathrm{mg} / \mathrm{dL}$ & TG & $137 \mathrm{mg} / \mathrm{dL}$ \\
APTT & $39.4 \mathrm{~s}$ & AMY & $126 \mathrm{U} / \mathrm{L}$ & HDL-C & $62 \mathrm{mg} / \mathrm{dL}$ \\
fibrinogen & $291 \mathrm{mg} / \mathrm{dL}$ & TP & $6.9 \mathrm{~g} / \mathrm{dL}$ & LDL-C & $113 \mathrm{mg} / \mathrm{dL}$ \\
FDP & $141 \mathrm{mEq} / \mathrm{L}$ & Alb & $4.0 \mathrm{~g} / \mathrm{dL}$ & FPG & $87 \mathrm{mg} / \mathrm{dL}$ \\
D-dimer & $7.4 \mu \mathrm{g} / \mathrm{mL}$ & T. bil & $0.5 \mathrm{mg} / \mathrm{dL}$ & $\mathrm{HbAlc}$ & $5.9 \%$ \\
CRP & $0.22 \mathrm{mg} / \mathrm{dL}$ & AST & $17 \mathrm{U} / \mathrm{L}$ & & \\
\hline
\end{tabular}

WBC: white blood cell count, RBC: red blood cell count, Hb: hemoglobin, Hct: hematocrit, Plt: platelet count, PT (INR): prothrombin time (international normalized ratio), APTT: activated partial thromboplastin time, FDP: fibrinogen degradation products, CRP: c-reactive protein , BUN: blood urea nitrogen, Cre: creatinine, UA: uric acid, TP: total protein, Alb: albumin, T. bil: total bilirubin, AST: aspartate aminotransferase, ALT: alanine aminotransferase, ALP: alkaline phosphatase, LDH: lactate dehydrogenase, $\gamma$ GTP: $\gamma$-glutamyl transpeptidase, CK: creatine kinase, TG: triglyceride, HDL-C: high-density lipoprotein cholesterol, LDL-C: low-density lipoprotein cholesterol, FPG: fasting plasma glucose, $\mathrm{HbAlc}$ : hemoglobin Alc

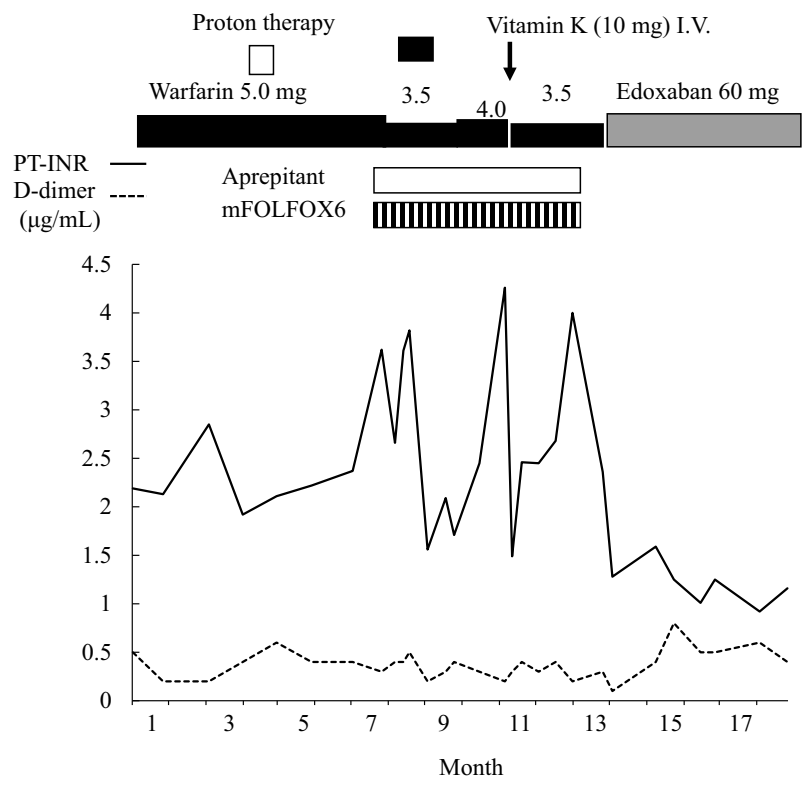

Figure 3. The time course of the warfarin response during chemotherapy for colon cancer metastasis to the liver. I.V.: intravenous infusion, mFOLFOX6: modified FOLFOX6

warfarin treatment was achieved, the patient was discharged with strict follow-up in our department to monitor his warfarin therapy.

Approximately 11 months after the second operation, MRI detected the recurrence of liver metastasis. This consisted of one mass of $2.3 \mathrm{~cm}$ in diameter in segment 8 of the liver and two small masses in segment 4. Proton therapy (68 GyE in eight fractions) was used because of the high risk of perioperative VTE. After proton therapy, modified FOLFOX6 was performed, and aprepitant (125 mg once per day at the first day of chemotherapy, followed by $80 \mathrm{mg}$ once per day) was administered. During the therapy, the patient's PT-INR fluctuated from 1.2 to 4.9 despite the active modification of the warfarin dose $(3.5-5.0 \mathrm{mg})$, and $10 \mathrm{mg}$ of vitamin $\mathrm{K}$ was administered intravenously to treat his high PT-INR (Fig. 3).

Approximately 1 month after the chemotherapy, edoxaban became available for the treatment of VTE in Japan. We recommended a switch from warfarin to edoxaban, based on the previous difficulties with warfarin and the possible need for additional chemotherapy if tumor recurrence developed, and discussed our recommendation with the patient and his family. Subsequently, edoxaban [60 mg, once daily, was selected on the basis of the patient's weight $(75 \mathrm{~kg})$, serum creatinine level $(1.22 \mathrm{mg} / \mathrm{dL})$, and a creatinine clearance (71 $\mathrm{mL} / \mathrm{min}$ )] was started in place of warfarin therapy. After changing to edoxaban, the patient's hematologic and coagulation indices remained stable and the patient's protein $\mathrm{C}$ and $\mathrm{S}$ activity increased (Table 2). Venous ultrasonography showed that organized thrombus was only present in the right femoral vein with good venous flow. No VTE events or hemorrhage occurred over the 1-year follow-up period. The patient's AT III activity did not change to a statistically significant extent after warfarin (AT III activity 47-51\%) was switched to edoxaban (48-54\%).

\section{Discussion}

Four DOACs, including one direct thrombin inhibitor (dabigatran) and three direct oral factor Xa inhibitors (apixaban, edoxaban, and rivaroxaban) have emerged as potential replacements for conventional treatments for the initial and long-term treatment of VTE (including VTE in cancer patients) (4). In Japan, edoxaban, rivaroxaban and apixaban are indicated for the treatment of VTE and are indicated for stroke prevention in patients with non-valvular atrial fibrillation.

The Hokusai-VTE study showed that the administration of edoxaban after initial heparin was not inferior to standard warfarin therapy after initial heparin and that it caused significantly less bleeding in a broad spectrum of patients with 
Table 2. Data of Coagulation and Fibrinolysis before and after Starting of Edoxaban.

\begin{tabular}{lcccc}
\hline & Before & 1M after & 4M after & 12M after \\
\hline PT-INR $(0.85-1.22)$ & 2.36 & 1.34 & 1.25 & 1.01 \\
APTT $(\mathrm{s})(25.2-34.5)$ & 39.6 & 37.9 & 38.0 & 30.6 \\
D-dimer $(\mu \mathrm{g} / \mathrm{mL})(<1.0)$ & 0.3 & 0.5 & 0.6 & 0.5 \\
Fibrinogen $(\mathrm{mg} / \mathrm{dL})(168-329)$ & 306 & 285 & 245 & 269 \\
FDP $(<5)(\mu \mathrm{g} / \mathrm{mL})$ & 1.3 & 1.9 & 1.2 & 1 \\
Fibrin monomer $(\mu \mathrm{g} / \mathrm{mL})(<6.1)$ & $<3.0$ & $<3.0$ & $<3.0$ & $<3.0$ \\
Protein C $(\%)(62-131)$ & 88 & 98 & 112 & 126 \\
Protein S $(\%)(60-150)$ & 107 & n.e. & 118 & 127 \\
AT III $(\%)(75-125)$ & 51 & 49 & 49 & 54 \\
Plasminogen $(\%)(75-150)$ & 104 & 92 & 108 & 126 \\
$\alpha 2$ PI $(\%)(80-120)$ & 99 & 102 & 107 & 113 \\
\hline
\end{tabular}

PT-INR: ptothrombin time-international ratio, APTT: activated partial prothrombin time, FDP: fibrin/fibrinogen degradation product, AT III: antithrombin III, $\alpha 2 \mathrm{PI}$ : $\alpha 2$-plasmin inhibitor

VTE, including those with severe pulmonary embolism (5). Edoxaban reduced the risk of symptomatic recurrent VTE and clinically relevant bleeding in East Asian patients by $36 \%$ and $44 \%$, respectively, in comparison to warfarin (6).

However, those studies did not investigate patients with VTE and AT III deficiency. AT III is a plasmatic $\alpha$ glycoprotein formed by a single peptide chain that inhibits thrombin and free Xa, IXa, VIIa plasmatic factors. AT III deficiency is associated with a higher risk of thromboembolic diseases. DOACs seem to be effective for the treatment of VTE associated with AT III deficiency. An animal experiment study demonstrated that edoxaban might be a better choice than AT III-dependent anticoagulants in patients with lower plasma AT III concentrations (7).

Moreover, the present patient showed PT-INR fluctuation in response to warfarin therapy after the start of chemotherapy (including 5-FU) for liver metastasis from colon cancer. Several previous reports have demonstrated an adverse interaction between warfarin and 5-FU in patients with cancer metastasis, primarily in patients with liver metastasis (8).

Although the precise mechanism of the interaction is not known, the inhibition of CYP $2 \mathrm{C} 9$ or $2 \mathrm{C} 19$ by 5 -FU is most likely to enhance the warfarin effect $(8,9)$, and hepatic impairment related to metastasis may affect the metabolism of drugs and clotting factors.

Other patient factors, such as vomiting, diarrhea, and the decreased intake of dietary vitamin $\mathrm{K}$, may result in an increase in the PT-INR, and these gastrointestinal symptoms might be the result of 5-FU treatment. Moreover, the present patient was treated with an anti-nausea agent, aprepitant, which induces CYP2C9 and which may reduce the warfarin effect. These factors likely complicated the patient's warfarin metabolism and resulted in a variable anticoagulant effect in the present patient. We hypothesize that edoxaban was useful in this situation because it did not interact with 5-FU.

There have been no studies on the long-term efficacy of DOACs, including edoxaban, in patients with symptomatic AT III deficiency. Moreover, there have been no studies of the use of edoxaban in patients with a permanently-inserted IVC filter. Further study is needed to evaluate the efficacy of DOACs in complicated patients.

In conclusion, edoxaban is useful for the treatment of VTE associated with AT III deficiency, especially when warfarin control is difficult due to chemotherapy.

Author's disclosure of potential Conflicts of Interest (COI).

Koji Maemura: Honoraria, Boehringer Ingelheim, Daiichi Sankyo, Bayer, MSD and Takeda.

\section{References}

1. Anderson FA Jr, Wheeler HB, Goldberg RJ, et al. A populationbased perspective of the hospital incidence and case-fatality rates of deep vein thrombosis and pulmonary embolism: the Worcester DVT Study. Arch Intern Med 151: 933-938, 1991.

2. Prandoni $\mathrm{P}$, Lensing AW, Cogo A, et al. The long-term clinical course of acute deep venous thrombosis. Ann Intern Med 125: 17, 1996.

3. Rodgers GM. Role of antithrombin concentrate in treatment of hereditary antithrombin deficiency. An update. Thromb Haemost 101: 806-812, 2009.

4. Posch F, Königsbrügge O, Zielinski C, Pabinger I, Ay C. Treatment of venous thromboembolism in patients with cancer: a network meta-analysis comparing efficacy and safety of anticoagulants. Thromb Res 136: 582-589, 2015.

5. Hokusai-VTE Investigators, Büller HR, Décousus H, Grosso MA, et al. Edoxaban versus warfarin for the treatment of symptomatic venous thromboembolism. N Engl J Med 369: 1406-1415, 2013.

6. Nakamura M, Wang YQ, Wang C, et al. Efficacy and safety of edoxaban for treatment of venous thromboembolism: a subanalysis of East Asian patients in the Hokusai-VTE trial. J Thromb Haemost 13: 1606-1614, 2015.

7. Fukuda T, Kamisato C, Honda Y, et al. Impact of antithrombin deficiency on efficacy of edoxaban and antithrombin-dependent anticoagulants, fondaparinux, enoxaparin, and heparin. Thromb Res 131: 540-546, 2013.

8. Davis DA, Fugate SE. Increasing warfarin dosage reductions associated with concurrent warfarin and repeated cycles of 5Fluorouracil therapy. Pharmacotherapy 25: 442-447, 2005.

9. Helsby NA, Lo WY, Thompson P, Laking GR. Do 5-fluorouracil therapies alter CYP2C19 metaboliser status? Cancer Chemother Pharmacol 66: 405-407, 2010.

The Internal Medicine is an Open Access article distributed under the Creative Commons Attribution-NonCommercial-NoDerivatives 4.0 International License. To 
Intern Med 55: 3285-3289, 2016 DOI: 10.2169/internalmedicine.55.7314

view the details of this license, please visit (https://creativecommons.org/licenses/ by-nc-nd/4.0/).

(C) 2016 The Japanese Society of Internal Medicine http://www.naika.or.jp/imonline/index.html 